\title{
Alimentação saudável e dificuldades para torná-la uma realidade: percepções de pais/responsáveis por pré-escolares de uma creche em Belo Horizonte/MG, Brasil
}

\author{
Healthy eating and the difficulties faced in making it a reality: \\ perceptions of parents/guardians of pre-school children \\ in Belo Horizonte/MG, Brazil
}

Isabel Cristina Bento ${ }^{1}$

Juliana Maria de Melo Esteves ${ }^{2}$

Thaís Elias França ${ }^{3}$

${ }^{1}$ Escola de Enfermagem, Universidade Federal de Minas Gerais. Pres. Antônio Carlos 6627, Pampulha. 31270-901 Belo Horizonte MG Brasil.evmepia@gmail. com

${ }^{2}$ Santa Casa de Misericórdia de Belo Horizonte.

${ }^{3}$ Faculdade de Minas.

\begin{abstract}
A cross-sectional qualitative study was conducted to establish the perceptions of 77 guardians of preschool children enrolled in a Child Day Care Center in Belo Horizonte/Minas Gerais State, regarding what is a healthy diet and the difficulties faced in having a healthy diet. The instrument used was a pretested semi-structured questionnaire containing leading questions obtained in face-to-face interviews. For data analysis, the Collective Subject Discourse technique was used, which elicited data organization of a verbal nature. It was revealed that the guardians have a notion of what healthy diet is, however their answers implied inadequate eating habits. They attributed insufficient financial resources, lack of time and ingrained eating habits as being the main difficulties in having a healthy diet. These three difficulties are the reasons given by some guardians who do not believe they have a healthy diet. The conclusion drawn is that the guardians need to have a better diet, because their eating habits influence their children's eating habits. These findings revealed the need for food and $n u-$ trition education strategies to enable the guardians to recognize and have a healthy diet.
\end{abstract}

Key words Food, Health promotion, Parents, Preschool, Child day care centers
Resumo Trata-se de um estudo transversal de abordagem qualitativa para conhecer as percepções de 77 responsáveis por pré-escolares matriculados em uma Creche em Belo Horizonte/MG, acerca do que entendem por alimentação saudável e suas dificuldades para se alimentarem de maneira adequada. O instrumento utilizado foi um questionário semiestruturado, previamente testado, contendo perguntas norteadoras obtidas por meio de entrevista face a face. Para a análise dos dados, utilizou-se a técnica do Discurso do Sujeito Coletivo, que permitiu organização de dados de natureza verbal. Observou-se que os responsáveis têm uma noção do que é uma alimentação saudável, a qual não é refletida em seus discursos que evidenciam uma prática alimentar inadequada. Apontaram como principais dificuldades para obter uma alimentação saudável os recursos financeiros, falta de tempo e hábito alimentar. Conclui-se que estes responsáveis precisam melhorar a sua alimentação, pois suas práticas alimentares influenciam as de seus filhos. Estes achados revelaram a necessidade de estratégias de educação alimentar e nutricional que possibilitem aos responsáveis reconhecer e ter uma alimentação saudável. Palavras-chave Alimentação, Promoção da saúde, Pais, Pré-escolar, Creche 


\section{Introdução}

Devido à crescente participação da mulher no mercado de trabalho e as mudanças na constituição familiar, observou-se um crescimento do número de crianças em idade pré-escolar em creches gratuitas, nas médias e grandes cidades ${ }^{1}$. Essas mulheres, muitas delas mães, alimentam-se fora de casa e raramente preparam as refeições para a família, tendo muitas vezes, como base de sua alimentação, produtos industrializados e de alta densidade energética, ricos em açúcares e gorduras, que vêm se incorporando às suas práticas alimentares com forte suporte publicitário².

É na fase pré-escolar que se inicia a formação dos hábitos e práticas alimentares das crianças, estes estarão ligados às práticas, escolhas, hábitos, preferências alimentares, modo de vida da família, e as condições que favorecem o consumo de determinado alimento tais como disponibilidade, estado emocional, cultura, relações sociais, dentre outros ${ }^{3}$. Percebe-se assim, que o ambiente familiar, representado pelos responsáveis, influencia e desempenha papel determinante no desenvolvimento das preferências e das práticas alimentares das crianças. ${ }^{4}$.

Práticas alimentares inadequadas têm causado distúrbios como a obesidade, que podem estar presentes na adolescência e na vida adulta, acarretando prejuízos psicológicos, sociais e em sua saúde geral ${ }^{5}$. Têm-se observado o crescente aumento da obesidade em crianças na idade pré -escolar ${ }^{6-8}$.

Sendo assim, objetivou-se conhecer as percepções dos responsáveis de uma Creche em Belo Horizonte/MG, acerca do que entendem por alimentação saudável e suas dificuldades para se alimentar de maneira saudável. Este é o primeiro passo para se conhecer e compreender os pensamentos e os sentimentos que sustentam as práticas alimentares inadequadas, do ponto de vista nutricional, bem como a forma de viver a alimentação no cotidiano, a qual reflete a história de cada um.

\section{Metodologia}

Realizou-se um estudo transversal em que se buscou adotar uma abordagem qualitativa com análise do Discurso do Sujeito Coletivo (DSC). Por meio da análise qualitativa foi possível descrever os significados que são socialmente construídos e explicitar a subjetividade da percepção dos indivíduos deste estudo, bem como compreender as percepções que envolvem o tema alimentação saudável e dificuldades para se alimentar de maneira adequada?

A amostra foi composta por todos os responsáveis por crianças de 1 ano a 6 anos de idade, devidamente matriculadas em uma Creche, localizada em Belo Horizonte/MG. Os responsáveis foram informados a respeito do objetivo do estudo e convidados a participar de forma voluntária pela Diretora da Creche. Todos os responsáveis concordaram em participar, e não houve nenhuma recusa. Eles assinaram um termo de consentimento livre e esclarecido, conforme princípios éticos da pesquisa envolvendo seres humanos, recomendados pela Resolução 466/12 $2^{10}$ do Conselho Nacional de Saúde. O estudo foi submetido e aprovado pelo Comitê de Ética em Pesquisa da Universidade FUMEC.

A coleta de dados ocorreu de agosto de 2013 a novembro de 2013 e foi obtida por meio de entrevista face a face, realizada por uma nutricionista e uma enfermeira responsáveis pelo estudo. Foram entrevistados 77 responsáveis, os quais compuseram a amostra deste estudo. O critério de inclusão era ser mãe, pai ou responsável pela criança devidamente matriculada na Creche no ano de 2013.

Utilizou-se um questionário semiestruturado, previamente testado, contendo variáveis socioeconômicas e demográficas tais como: sexo; parentesco com a criança (mãe, pai, responsável); número de filhos; idade; escolaridade (analfabeto, ensino fundamental, ensino médio, ensino superior, pós-graduação); ocupação [trabalha o dia inteiro, trabalha meio período, não trabalha, desempregado(a), aposentado(a)]; estado conjugal [solteiro(a), casado(a), união estável, divorciado(a), separado(a)]; renda familiar (renda total de todos da casa). O valor do salário mínimo vigente no período da aplicação do questionário era de $\mathrm{R} \$ 678,00$. Também foram coletadas as seguintes questões: onde busca informações sobre alimentação (não me interesso pelo assunto, revistas, televisão, internet, jornais, nutricionista, médico, outros profissionais de saúde); quais os fatores que influenciam em suas escolhas alimentares (preço, gosto, praticidade, falta de tempo, comprar em lugares perto de casa) - nestas duas questões, foi possível aos responsáveis escolherem mais de uma opção; e quais os alimentos mais frequentes em sua alimentação. Além disto, foram feitas as perguntas norteadoras, a saber: (1) O que você entende por alimentação saudável?; (1.1) Você acredita que sua alimentação é saudável? (Sim, Não); Caso sua resposta tenha 
sido "não", diga por que acredita que sua alimentação não é saudável?; (2) Que dificuldades encontra para se alimentar de maneira saudável?

As informações foram armazenadas em banco construído para este estudo.Utilizou-se o Programa Statistical Package for Social Sciences (SPSS), versão 15.0 para realizar as análises descritivas dos dados, tais como: distribuição de frequência (simples e cruzadas), análise de medidas de tendência central e medidas de dispersão.

Utilizou-se a técnica do DSC para analisar as perguntas norteadoras. O DSC é uma estratégia metodológica em que "os discursos dos depoimentos não se anulam ou se reduzem a uma categoria comum unificadora, já que o que se busca fazer é reconstruir, com pedaços de discursos individuais, como em um quebra-cabeça, tantos discursos-síntese quantos se julguem necessários para expressar um determinado modo de pensar ou representação social sobre um fenômeno" ${ }^{11}$. Esta técnica consistiu em selecionar, de cada resposta individual, dos responsáveis pelas crianças da creche, as expressões-chave, que são trechos mais significativos das respostas. As expressõeschave correspondem a ideias centrais, que são a síntese do conteúdo do discurso. De posse das expressões-chave das ideias centrais, foram construídos os discursos síntese que são os DSC, em primeira pessoa do singular, e que refletiram e expressaram o pensamento do grupo de responsáveis pelas crianças ${ }^{12}$ sobre alimentação saudável e dificuldades para adotá-la.

\section{Resultados e discussão}

Na Tabela 1 são apresentados os dados de caracterização sociodemográfica e comportamental dos responsáveis $(\mathrm{n}=77)$ pelas crianças da creche. Observou-se, na Tabela 1, predominância de responsáveis do sexo feminino, todas mães, com uma média de 2,21 $\pm 1,03$ filhos, média de idade de 31,43 anos $\pm 6,48$ anos, a maioria com ensino médio, que trabalham o dia todo, são solteiras, com renda familiar de 1 a 2 salários mínimos, que relatam buscar informações sobre alimentação na televisão e que têm o preço dos alimentos como principal fator que as influencia na compra dos mesmos.

Historicamente, a mulher é vista como a cuidadora da casa e da família, e com o crescente número de mulheres, atualmente, no mercado de trabalho, muitas mudanças na vida e estruturas familiares são observadas ${ }^{13}$. Existem lares onde as mulheres assumem sozinhas a casa, o trabalho
Tabela 1. Características sociodemográficas e comportamentais dos responsáveis pelas crianças da creche - Belo Horizonte/MG, 2013.

\begin{tabular}{|c|c|c|}
\hline Variáveis & $\mathbf{n}$ & $(\%)$ \\
\hline \multicolumn{3}{|l|}{ Sexo } \\
\hline Feminino & 75 & 97,4 \\
\hline Masculino & 2 & 2,6 \\
\hline
\end{tabular}

\begin{tabular}{|c|c|c|}
\hline \multicolumn{3}{|l|}{ Parentesco com a crıança } \\
\hline Mãe & 74 & 96,1 \\
\hline Pai & 2 & 2,6 \\
\hline Responsável & 1 & 1,3 \\
\hline \multicolumn{3}{|l|}{ Número de filhos } \\
\hline 1 filho & 22 & 28,6 \\
\hline 2 filhos & 26 & 33,8 \\
\hline 3 filhos & 22 & 28,6 \\
\hline 4 filhos & 6 & 7,8 \\
\hline 6 filhos & 1 & 1,2 \\
\hline \multicolumn{3}{|l|}{ Idade } \\
\hline 20 a 29 anos & 33 & 42,9 \\
\hline 30 a 39 anos & 37 & 48,1 \\
\hline 40 a 49 anos & 7 & 9 \\
\hline \multicolumn{3}{|l|}{ Escolaridade } \\
\hline Analfabeto & 2 & 2,6 \\
\hline Ensino Fundamental & 30 & 39 \\
\hline Ensino Médio & 32 & 41,6 \\
\hline Ensino Superior & 11 & 14,2 \\
\hline Pós-graduação & 2 & 2,6 \\
\hline \multicolumn{3}{|l|}{ Ocupação } \\
\hline Trabalha o dia todo & 46 & 59,7 \\
\hline Trabalha meio período & 14 & 18,2 \\
\hline Não trabalha & 9 & 11,7 \\
\hline Desempregado(a) & 8 & 10,4 \\
\hline \multicolumn{3}{|l|}{ Estado conjugal } \\
\hline Solteiro(a) & 32 & 41,5 \\
\hline Casado(a) & 18 & 23,4 \\
\hline União estável & 20 & 26 \\
\hline Divorciado(a) & 4 & 5,2 \\
\hline Separado(a) & 3 & 3,9 \\
\hline \multicolumn{3}{|l|}{ Renda familiar ${ }^{*}$} \\
\hline menos de 1 salário mínimo & 22 & 28,6 \\
\hline 1 a 2 salários mínimos & 29 & 37,7 \\
\hline 2 a 3 salários mínimos & 13 & 16,8 \\
\hline 3 a 4 salários mínimos & 6 & 7,8 \\
\hline 4 a 5 salários mínimos & 7 & 9,1 \\
\hline
\end{tabular}

continua

e os filhos, sem a figura masculina. Observa-se, também, relações entre homens e mulheres, fora do casamento, em que os homens não participam da vida dos filhos, mesmo dividindo a mesma moradia $^{14}$.

Segundo França e Schimanski ${ }^{14}$, "as atividades consideradas femininas estão sempre associadas com a função de reprodução, em geral, são 


\begin{tabular}{lrr}
\hline \multicolumn{1}{c}{ Tabela 1. continuação } & & \\
\hline \multicolumn{1}{c}{ Variáveis } & $\mathbf{n}$ & $(\%)$ \\
\hline $\begin{array}{l}\text { Onde busca informações sobre } \\
\text { alimentação }\end{array}$ & & \\
Não me interesso pelo assunto & 7 & 9,1 \\
Revista & 15 & 19,5 \\
Televisão & 34 & 44,2 \\
Internet & 18 & 23,4 \\
Jornais & 11 & 14,3 \\
Nutricionista & 17 & 22,1 \\
Médico & 25 & 32,5 \\
Fatores que influenciam nas escolhas & & \\
alimentares & & \\
Preço & 35 & 45,5 \\
Gosto & 33 & 42,9 \\
Praticidade & 23 & 29,9 \\
Falta de tempo & 14 & 18,2 \\
Comprar em lugares perto de casa & 12 & 15,6 \\
Alimentos mais frequentes na & & \\
alimentação & & \\
Pizza & 54 & 70,1 \\
Ovo Frito & 54 & 70,1 \\
Macarrão & 54 & 70,1 \\
Sanduiche & 54 & 70,1 \\
Batata & 50 & 64,9 \\
Suco em pó & 47 & 61,0 \\
\hline
\end{tabular}

"Salário mínimo: R\$ 678,00. **mais de uma opção foi escolhida pelo responsável.

as atividades que estão relacionadas ao espaço privado da família e à produção de valores de uso para o consumo familiar. Já as atividades destinadas à produção social (e que são desenvolvidas no espaço público) são tidas como uma atribuição masculina”.

Segundo o Instituto Brasileiro de Geografia e Estatística (IBGE) ${ }^{15}$, na faixa etária de 25 a 49 anos, as mulheres exercem atividades remuneradas e têm filhos pequenos em casa, sendo que a quantidade de filhos em famílias de baixa renda é maior se comparada a famílias com melhores condições financeiras ${ }^{16}$.

Vale salientar que uma expressiva parcela da população deste estudo são mães na fase adulta jovem (20 a 29 anos), que não estão preparadas para atender às necessidades nutricionais de seus filhos, o que pode ser um reflexo da ausência de informações e orientações, bem como a possibilidade de falta de recursos para exercer a maternidade, como constatado no estudo de Reia e Ramos ${ }^{17}$.

Sabe-se que mulheres menos escolarizadas têm postos de trabalho menos rentáveis, o que as impede de adquirir bens e serviços que facilitem ou reduzam o seu trabalho doméstico, dentre eles a alimentação feita em $\operatorname{casa}^{13}$. A baixa renda também impede que suas necessidades e de seus familiares, como encargos públicos (água, luz, telefone, aluguel), sejam atendidas. Estes encargos consomem grande parte de seus recursos, reduzindo aqueles destinados à educação, alimentação, saúde e lazer.

A baixa escolaridade está associada ao poder de compra, acesso a informações em saúde, escolha incorreta de alimentos e maior influência da publicidade na compra dos alimentos ${ }^{18,19}$.

A renda associada a uma estrutura familiar em que os responsáveis são solteiros e, muitas vezes, separados, pode interferir no crescimento e desenvolvimento da criança, uma vez que a presença dos responsáveis é fundamental para a construção do caráter, personalidade e hábitos de vida, dentre estes o alimentar ${ }^{20}$.

Em relação à busca de informações sobre alimentação, a televisão é o veículo mais procurado para tais informações, sendo a grande disseminadora de propagandas com mensagens persuasivas, atraentes e marcantes sobre alimentos, a maioria deles produtos energéticos de alta densidade nutricional, enfim produtos ricos em gorduras, açúcares e sódio e pobres em fibras alimentares que podem causar enfermidades, mal à saúde e que acabam por compor a dieta dos indivíduos ${ }^{21}$.

Esses alimentos são caracterizados como práticos, de consumo imediato, e que facilitam a preparação das refeições em casa. Além disso, a propaganda destes alimentos estimula o seu consumo pelas crianças, por meio da associação de personagens de desenhos infantis, artistas famosos, brindes e coleç̃oes de brinquedos ${ }^{22}$, o que pode contribuir para obesidade ${ }^{20}$. Crianças com idade inferior a 5 anos são influenciadas pelos comerciais e seus efeitos especiais, adotando práticas e estereótipos veiculados pela mídia ${ }^{23}$.

Santos et al. ${ }^{24} \mathrm{em}$ seu estudo sobre a influência da televisão nos hábitos, costumes e comportamentos alimentares, relataram que o aumento do tempo de exposição das pessoas ao conteúdo divulgado pela televisão pode influenciar nas escolhas e hábitos alimentares, contribuindo para o consumo inadequado de alimentos pela população, tais como as gorduras e os doces. E ainda concluíram que a mídia televisiva não tem contribuído para um estilo de vida saudável.

Desse modo, por exercerem influências nas escolhas alimentares da população, a mídia televisiva deveria se comprometer a divulgar alimentos saudáveis e/ou introduzir sinais de alerta para o consumo indiscriminado de alimentos com alta 
densidade energética, a fim de contribuir para que a população tenha hábitos alimentares saudáveis ${ }^{24}$.

Quanto aos fatores que influenciam as escolhas alimentares dos responsáveis, o preço aparece como fator preponderante nas decisões de compra, o que compromete a qualidade da dieta. Restrições econômicas à compra do alimento, como as vivenciadas por indivíduos de baixa renda, conduzem a dietas com baixo consumo de frutas e hortaliças e de alta densidade energética, principalmente alto consumo de cereais processados, açúcar e óleo ${ }^{25,26}$.

Batalha et al. ${ }^{27}$ em seu estudo sobre a percepção dos indivíduos acerca do preço de produtos alimentícios, demonstrou que a maioria dos consumidores, nos diferentes níveis de renda, têm a percepção de que o preço dos alimentos é alto. Os autores concluíram que as variáveis preço e renda influenciam nas decisões de compra, entretanto, não podem ser consideradas como variáveis isoladas para uma interpretação do comportamento do consumidor nem como a proporcionalidade entre renda e consumo.

Por meio de seus relatos acerca dos alimentos mais frequentes em seu cotidiano, observou-se que a pizza, ovo frito, macarrão, sanduiche, batata, e o suco em pó foram os mais citados (Tabela 1). Souza et al. ${ }^{28}$, em seu estudo sobre caracterização do consumo alimentar mais frequente na população brasileira, revelaram que a batata, macarrão, sucos e refrescos foram alguns dos alimentos mais apontados pelos adultos.

Com relação ao DSC, este permitiu conhecer os pensamentos dos responsáveis pelas crianças de uma creche, por meio do resgate de suas ideias e opiniões coletivas sobre o que entendem por alimentação saudável e as dificuldades para torná-la realidade. O resultado da análise dos dados culminou no DSC, ou seja, o conjunto de falas transformou-se em uma única fala que representa essa coletividade ${ }^{12}$.

Da primeira pergunta, 7 (sete) discursos-síntese foram elaborados na primeira pessoa do singular. Identificou-se que a alimentação saudável sob o ponto de vista dos responsáveis é percebida a partir de diferentes dimensões, como a questão da alimentação variada, equilibrada, natural, regular e rica em nutrientes; que contenha frutas, verduras, legumes, arroz, feijão, carnes brancas, cereais, leites e derivados; evitando gorduras e açúcares; tomando água e alimentando-se em horários certos (Quadro 1).

Achados similares foram encontrados no estudo de Bento ${ }^{29}$, que identificou as representações sociais sobre a adoção de uma alimentação saudável pelos usuários dos restaurantes populares de Belo Horizonte. Neste estudo, verificou-se que os sujeitos compartilham da representação de que, para se ter uma alimentação saudável, deve-se regularizar os horários das refeições, alimentar-se mais vezes durante o dia, e mastigar bem os alimentos. Ainda, cortar e reduzir os alimentos ricos em carboidratos e gorduras.

No estudo de Marinho et $a .^{30}$, em que analisaram as práticas e percepções dos gestores de creches sobre alimentação saudável para crianças, os gestores das creches relataram que uma alimentação saudável é aquela composta por arroz, feijão, frutas, hortaliças, devendo ser variada e rica em nutrientes, corroborando com os resultados do presente estudo.

Dentre os discursos, destacam-se pela similaridade das ideias centrais os, DSC.1B, DSC.1C, DSC.1E, DSC.1F, pautados na representação social de comer frutas, verduras e legumes.

Achados similares foram encontrados na pesquisa de Barbosa et al. ${ }^{31}$, em que objetivaram conhecer a percepção de responsáveis e recreadores sobre diferentes representações gráficas do guia alimentar para crianças de dois a três anos de idade. Eles discutem que as frutas e legumes são os alimentos presentes em todas as falas de responsáveis e recreadores, quando se perguntou o que é uma alimentação saudável.

Também no estudo de Bento ${ }^{29}$ as frutas, verduras e legumes estão presentes nas falas dos usuários dos restaurantes populares de Belo Horizonte, quando se perguntou o tipo de mudança que têm feito ou esperam fazer em sua alimentação.

Sabe-se que o conceito de alimentação saudável é construído de acordo com as experiências de vida, fontes de informação, mudanças nas regras sociais, prioridades, restrições, valores, fatores antropológicos e psicológicos, bem como as características demográficas e culturais. Este conceito pode ser alterado ao longo da vida e variar em complexidade e contexto ${ }^{3}$.

De acordo com o Guia Alimentar da População Brasileira, publicado pelo Ministério da Saúde (Guia Alimentar) 32, “a alimentação saudável deve fornecer água, carboidratos, proteínas, lipídios, vitaminas, fibras alimentares e minerais, os quais são insubstituíveis e indispensáveis ao bom funcionamento do organismo. A diversidade dietética que fundamenta o conceito de alimentação saudável pressupõe que nenhum alimento específico ou grupo deles, isoladamente, é suficiente para fornecer todos os nutrientes necessários a uma boa nutrição e consequente manutenção da 
Quadro 1. Proporção das ideias centrais referentes às percepções dos responsáveis pelas crianças da Creche, e o DSC, com relação à primeira pergunta norteadora: O que você entende por alimentação saudável? - Belo Horizonte/ MG - 2013.

\begin{tabular}{|c|c|c|c|}
\hline Ideias Centrais (IC) & Discurso do Sujeito Coletivo (DSC) & $\begin{array}{l}\text { No de } \\
\text { respostas }\end{array}$ & $\%$ \\
\hline $\begin{array}{l}\text { IC.1A -Alimentação capaz de } \\
\text { oferecer todos os nutrientes }\end{array}$ & $\begin{array}{l}\text { DSC-1A - Para mim uma alimentação saudável é capaz } \\
\text { de oferecer todos os nutrientes necessários para proteger } \\
\text { o organismo contra doenças, promover saúde e bem } \\
\text { estar, como por exemplo: carboidratos, proteina, fibras, } \\
\text { vitaminas, cálcio e ferro. Todos os alimentos devem ser } \\
\text { incluídos no meu dia-a-dia. }\end{array}$ & 18 & 23,4 \\
\hline $\begin{array}{l}\text { IC.1B- Comer frutas, verduras e } \\
\text { legumes/ carnes brancas, arroz, } \\
\text { feijão / derivados do leite/ evitar } \\
\text { gorduras e açúcares }\end{array}$ & $\begin{array}{l}\text { DSC.1B - É quando eu me alimento bem com alimentos } \\
\text { saudáveis como frutas, verduras, legumes, arroz, feijão, } \\
\text { carne branca, iogurte, queijos brancos, enfim alimentos } \\
\text { livres de gordura e evito alimentos gordurosos e açúcar. }\end{array}$ & 15 & 19,5 \\
\hline $\begin{array}{l}\text { IC.1C-Comer frutas, verduras } \\
\text { e legumes, arroz, feijão/tomar } \\
\text { água/ comer em horários certos }\end{array}$ & $\begin{array}{l}\text { DSC.1C - É quando eu como alimentos saudáveis como } \\
\text { as frutas, verduras legumes, produtos naturais, carnes } \\
\text { brancas sempre em horários certos e, beber muita água do } \\
\text { decorrer do dia, evito produtos industrializados, gorduras, } \\
\text { principalmente gordura trans, frituras, refrigerante e } \\
\text { como o menos possível de açúcar. }\end{array}$ & 11 & 14,3 \\
\hline $\begin{array}{l}\text { IC.1D- Alimentação variada, } \\
\text { equilibrada, natural, regular/ } \\
\text { comer frutas, verduras, legumes, } \\
\text { cereais }\end{array}$ & $\begin{array}{l}\text { DSC. 1D - Quando eu como alimentos variados, naturais } \\
\text { de forma regular e que me oferecem todos os nutrientes } \\
\text { de forma equilibrada. Para eu ter boa saúde, preciso } \\
\text { comer frutas, verduras, legumes e cereais. }\end{array}$ & 7 & 9,1 \\
\hline $\begin{array}{l}\text { IC1.E-Comer frutas, verduras e } \\
\text { legumes }\end{array}$ & $\begin{array}{l}\text { DSC.1E - Para eu ter uma alimentação saudável preciso } \\
\text { comer frutas, verduras e legumes. }\end{array}$ & 6 & 7,8 \\
\hline $\begin{array}{l}\text { IC.1F- Comer frutas, verduras } \\
\text { e legumes, leites e derivados/ } \\
\text { comer em horários certos / evitar } \\
\text { açúcares e gorduras }\end{array}$ & $\begin{array}{l}\text { DSC.1F - Tenho alimentação saudável quando como } \\
\text { na hora certa, verduras de folhas frescas, frutas, leite, } \\
\text { derivados do leite, suco natural e evito muita gordura, } \\
\text { evitando frituras e doces. }\end{array}$ & 5 & 6,5 \\
\hline \multirow[t]{3}{*}{$\begin{array}{l}\text { IC.1G - Comer em horários } \\
\text { certos }\end{array}$} & $\begin{array}{l}\text { DSC.1G - Preciso estabelecer horários certos para me } \\
\text { alimentar todos os dias para eu ter uma alimentação } \\
\text { saudável. }\end{array}$ & 4 & 5,2 \\
\hline & Ideia Central Excluída & 11 & 14,3 \\
\hline & Total & 77 & 100,0 \\
\hline
\end{tabular}

saúde”. Ainda segundo o Guia Alimentar ${ }^{32}$, todos os grupos de alimentos devem compor a dieta diária, porém nem todos os grupos alimentares foram citados pelos responsáveis pelas crianças do presente estudo.

Observou-se que, de uma maneira geral, os responsáveis têm uma noção do que é uma alimentação saudável, e é possível que tenham adquirido esse conhecimento por meio da televi- são, do médico, da internet e do(a) nutricionista, como pode ser constatado neste estudo (Tabela 1). A televisão e a internet permitem a divulgação de informações sobre alimentação e torna acessível à população em geral conceitos e atitudes relativas à saúde e à alimentação, além de possuírem um grande potencial para influenciar as práticas alimentares ${ }^{33}$. De um modo geral as pessoas tendem a mesclar as informações obtidas a partir 
de diversos veículos, não só as oriundas dos médicos e artigos de jornais e revistas como também por meio de conversas com amigos ${ }^{34}$.

Com relação às gorduras e os açúcares, percebe-se pelos discursos DSC.1B e DSC.1F, que esses indivíduos não têm esclarecimentos sobre a importância das gorduras na alimentação e nem o fato de que existem gorduras benéficas para o nosso organismo, como as gorduras monoinsaturadas, como ômega 9, e poli-insaturadas, como ômega 3 e ômega 6, que em quantidades adequadas contribuem para a saúde cardiovascular ${ }^{35}$. Por outro lado, o consumo excessivo de gorduras totais, gorduras saturadas, gorduras trans e alimentos de elevada densidade energética são prejudiciais à saúde ${ }^{32}$.

Para indivíduos saudáveis as gorduras e açúcares não devem ser retirados da alimentação, mas reduzidos, sendo consumidos dentro das faixas recomendadas para a boa alimentação e nutrição ${ }^{32}$. Segundo o Guia Alimentar ${ }^{32}$, a redução do consumo de alimentos com alta concentração de açúcar e gordura diminui o risco de ocorrência de obesidade e suas comorbidades.

Os estudos de Santos et al. ${ }^{21}$, que analisaram a quantidade e o horário das propagandas veiculadas pela televisão sobre produtos alimentícios, e Menezes et al. ${ }^{36}$, que identificaram o significado de alimentação saudável para pessoas idosas e dificuldades encontradas no cotidiano dos mesmos, ambos verificaram que as pessoas tendem a considerar as frutas, verduras e legumes sempre como alimentos promotores da saúde e as gorduras e açúcares como alimentos que devem ser retirados da alimentação.

Um estudo nacional e um estudo internacional apontaram que o consumo de frutas e hortaliças estão abaixo das recomendações para se ter uma alimentação saudável ${ }^{28,37}$. Os indivíduos têm consumido uma alimentação rica em gorduras, açúcares, bebidas com adição de açúcares, e alto consumo de calorias ${ }^{38,39}$.

O discurso DSC.1A e DSC.1D revelam que alguns indivíduos consideram a alimentação saudável como aquela que contém todos os nutrientes, é equilibrada, variada e oferecida de modo regular e natural. Foram citados um princípio (variedade) e dois atributos de uma alimentação saudável (variedade e equilíbrio), ambos, estabelecidos pelo Guia Alimentar ${ }^{32}$.

Para que a dieta forneça todos os nutrientes necessários para atender às demandas fisiológicas e garantir uma alimentação adequada, é necessário que seja composta por todos os grupos alimentares. A alimentação regular e natural são itens que fazem parte das diretrizes para uma alimentação saudável do Guia Alimentar ${ }^{32}$.

A conduta de um indivíduo quanto à alimentação abrange tudo que se apreende ao longo de sua vida em termos de práticas, habilidades, conhecimentos, informações, significados, representações, valores, percepções, opiniões, ou seja, tudo o que ele pensa, sente e faz com relação ao comer e à comida ${ }^{3}$.

Com relação a segunda pergunta, do total de responsáveis $59,7 \%(\mathrm{n}=46)$ acreditam ter uma alimentação saudável e 40,3\% (n=31) não acreditam ter uma alimentação saudável (Quadro 2). Estes discursos revelam um hábito arraigado da ingestão de alimentos ricos em gorduras, carboidratos e açúcares (Quadro 2). A justificativa para o consumo destes alimentos ditos "pesados" está relacionada a alguns fatores como o gosto, o preço, a praticidade e a falta de tempo (Quadro 3). Esta visão pode estar associada a experiências de vida, regras familiares, além da possibilidade de terem feito parte da infância destes responsáveis.

As mães que trabalham muitas vezes não querem preparar refeições no final de semana, período de descanso e, assim, o hábito de ingerir "alimentos pesados" é passado aos filhos, que podem acabar por não aceitar a comida da creche durante a semana, a qual segue um cardápio feito por um nutricionista.

Barbosa et al. ${ }^{40}$ compararam o consumo alimentar durante a semana com o do final de semana de crianças de uma creche, com base na pirâmide alimentar de crianças brasileiras de dois e três anos. Os autores constataram que, no final de semana, é maior a inadequação da dieta das crianças quando comparada com a oferecida na creche durante a semana.

No estudo de Marinho et $\mathrm{al}^{30}$, em que, ao examinarem as práticas e percepções dos gestores de creches sobre alimentação saudável, verificaram que a dificuldade de aceitação do cardápio da creche pelas crianças foi uma das questões relatadas pelos gestores, sendo justificada principalmente pelos hábitos alimentares inadequados anteriores à creche.

A Creche é um ambiente propício para vivência e formação de hábitos, pois as crianças passam parte significativa de seu tempo, alimentamse coletivamente e constroem valores ${ }^{3}$. As informações que as crianças recebem são construídas a partir de conhecimentos dos coleguinhas, das professoras e dos familiares ${ }^{3}$. Sendo assim, os responsáveis devem ser estimulados e sensibilizados a fazer as melhores escolhas alimentares, e estas devem promover saúde, prazer e prevenir doen- 
Quadro 2. Proporção das ideias centrais referentes às percepções dos responsáveis pelas crianças da Creche, e o DSC, com relação à pergunta: "Você acredita que sua alimentação é saudável?” - Belo Horizonte/MG- 2013.

\begin{tabular}{|l|l|c|c|}
\hline \multicolumn{1}{|c|}{ Ideias Centrais (IC) } & \multicolumn{1}{|c|}{ Discurso do Sujeito Coletivo (DSC) } & $\begin{array}{c}\text { No de } \\
\text { respostas }\end{array}$ & $\%$ \\
\hline $\begin{array}{l}\text { IC1.1A - Comer alimentos } \\
\text { gordurosos/doces/massas/ } \\
\text { alimentos industrializados/ } \\
\text { alimentação com baixo valor } \\
\text { nutricional }\end{array}$ & $\begin{array}{l}\text { DSC1.1A - Consumo uma quantidade maior de alimentos } \\
\text { ricos em gorduras, doces massas, alimentos industrializados, } \\
\text { tornando minha alimentação mais calórica e com baixo valor } \\
\text { nutricional. Eu como muita besteira, enfim tudo que faz mal } \\
\text { a saúde, mas é difícil ficar sem estes alimentos. }\end{array}$ & 10 & 32,3 \\
\hline IC1.1B - Hábito & $\begin{array}{l}\text { DSC1.1B - Tenho o hábito e gosto de comer muita fritura } \\
\text { nem sempre como frutas e legumes porque não gosto. }\end{array}$ & 7 & 22,6 \\
\hline $\begin{array}{l}\text { IC1.1C- Comer fora de casa/ } \\
\text { comer fora de hora/Comida } \\
\text { pesada e desequilibrada }\end{array}$ & $\begin{array}{l}\text { DSC1.1C - Eu sempre almoço fora de casa, geralmente muito } \\
\text { fora de hora, comida pesada (feijoada, galinhada, lasanha, } \\
\text { etc.), e sempre como comida desequilibrada. }\end{array}$ & 9 \\
\hline $\begin{array}{l}\text { IC1.1D - Falta de tempo/ } \\
\text { condição financeira }\end{array}$ & $\begin{array}{l}\text { DSC1.1D - Minha vida é muito corrida, o tempo é pouco } \\
\text { para preparar as coisas aí acabo comendo qualquer coisa ou o } \\
\text { que for feito mais rápido. Além disto, as coisas são muito caras } \\
\text { e eu tenho que excluir algumas coisas para poder comprar } \\
\text { outras e isto atrapalha ter uma alimentação saudável. }\end{array}$ & 5 \\
\hline
\end{tabular}

ças. Deve-se, também, buscar formas de orientá -los acerca de suas práticas alimentares, uma vez que estas podem influenciar nas escolhas alimentares de seus filhos e refletir em sua saúde e qualidade de vida.

Da segunda pergunta, 9 (nove) discursossíntese foram elaborados na primeira pessoa do singular (Quadro 3). As dificuldades identificadas pelos responsáveis, para se alimentarem de maneira saudável, são condizentes com o estudo de Bento ${ }^{29}$, em que se identificou as representações sociais sobre as dificuldades dos usuários dos restaurantes populares de Belo Horizonte/ MG para se alimentarem de maneira saudável. Bento $^{29}$ verificou que os usuários de seu estudo apontaram como dificuldades a condição financeira e a falta de tempo para preparar e comprar alimentos saudáveis.

Para os responsáveis, as dificuldades para se alimentarem de maneira saudável giram, em maior proporção, em torno da condição financeira, falta de tempo e do hábito. E em menor proporção em torno de comer verduras e legumes, comer nos horários certos e cortar/evitar alimentos gordurosos e enlatados (Quadro 3).
Esses relatos podem ser explicados pelo fato da maioria dos responsáveis trabalhar fora de casa e serem mães.

A inserção da mulher no mercado de trabalho provocou mudanças na organização dos valores e hábitos alimentares, da própria mulher e de sua família. No estudo de Lelis et al. ${ }^{2}$, as mulheres relataram alterações nos hábitos alimentares em decorrência de sua inserção no mercado de trabalho, realizando refeições rápidas e a substituição das grandes refeições (almoço e jantar) por lanches.

Tem-se observado no Brasil e em outros países um aumento do consumo de refeições rápidas e de custo semelhante a um lanche comum ${ }^{41}$. Percebe-se, então, a necessidade de orientar as pessoas a respeito de escolhas mais saudáveis, coerentes com suas necessidades nutricionais e alimentares, que venham ao encontro a sua situação econômica, disponibilidade de tempo, saúde e prazer ${ }^{37,42}$.

Pode-se observar que as ideias centrais IC.2C - "Hábito" e IC.2D - “Condição financeira e falta de tempo" (Quadro 3), também, foram apontados como motivos pelos quais os responsáveis 
Quadro 3. Proporção das ideias centrais referente às percepções dos responsáveis pelas crianças da Creche e o DSC, com relação à segunda pergunta norteadora: “Que dificuldades encontra para se alimentar de maneira saudável?” - Belo Horizonte/MG - 2013.

\begin{tabular}{|c|c|c|c|}
\hline Ideias Centrais (IC) & Discurso do Sujeito Coletivo (DSC) & $\begin{array}{l}\text { No de } \\
\text { respostas }\end{array}$ & $\%$ \\
\hline IC.2A- Condição financeira & $\begin{array}{l}\text { DSC-2A - Hoje em dia só é preciso eu ter um pouco mais de } \\
\text { dinheiro para ter uma boa alimentação, porque o meu salário } \\
\text { é muito baixo e não é todo dia que tenho dinheiro para } \\
\text { comprar de tudo. }\end{array}$ & 18 & 23,4 \\
\hline IC.2B-Falta de tempo & $\begin{array}{l}\text { DSC-2B - Eu não tenho tempo para preparar comida } \\
\text { saudável porque o dia a dia é muito corrido, tenho muito } \\
\text { serviço em casa e do trabalho que faço, fico muito tempo fora } \\
\text { de casa. }\end{array}$ & 15 & 19,5 \\
\hline IC.2C-Hábito & $\begin{array}{l}\text { DSC-2C - Preciso criar o hábito de comer de maneira } \\
\text { saudável, porque das coisas saudáveis às vezes esquecemos } \\
\text { porque são raras de se comer e porque gosto de coisas que não } \\
\text { são saudáveis, mas me policio diariamente, na minha casa a } \\
\text { alimentação é com pouquíssima gordura, leite, toddy light. }\end{array}$ & 9 & 11,7 \\
\hline $\begin{array}{l}\text { IC.2D-Condição financeira e } \\
\text { falta de tempo }\end{array}$ & $\begin{array}{l}\text { DSC-2D - Meu tempo é curto e me falta dinheiro pois os } \\
\text { alimentos são muito caros. }\end{array}$ & 7 & 9,1 \\
\hline $\begin{array}{l}\text { IC. } 2 \mathrm{E} \text {-Comer verduras } \\
\text { e legumes }\end{array}$ & DSC-2E - Não gosto de comer verduras e legumes. & 5 & 6,5 \\
\hline $\begin{array}{l}\text { IC. } 2 \mathrm{~F} \text {-Falta de tempo e } \\
\text { hábito }\end{array}$ & $\begin{array}{l}\text { DSC-2F - Não tenho tempo e por isto minhas refeições são } \\
\text { mais práticas. Além disto, gosto muito de consumir porcarias. }\end{array}$ & 3 & 3,9 \\
\hline IC.2G -Não tem dificuldade & $\begin{array}{l}\text { DSC- } 2 \mathrm{G} \text { - Não encontro nenhuma dificuldade, como de } \\
\text { tudo e acredito que é só a pessoa querer se alimentar de tudo } \\
\text { dentro dos limites. }\end{array}$ & 3 & 3,9 \\
\hline $\begin{array}{l}\text { IC. } 2 \text { H-Comer nos horários } \\
\text { certos }\end{array}$ & DSC-2H - Eu tenho dificuldade de comer nos horários certos. & 2 & 2,6 \\
\hline \multirow[t]{3}{*}{$\begin{array}{l}\text { IC.2I-Cortar e evitar } \\
\text { alimentos gordurosos e } \\
\text { enlatados }\end{array}$} & $\begin{array}{l}\text { DSC-2I - É difícil para mim deixar de comer alimentos } \\
\text { pesados, gordurosos, enlatados porque são muito gostosos. Eu } \\
\text { sei que preciso evitar frituras, gorduras e produtos enlatados. }\end{array}$ & 2 & 2,6 \\
\hline & Ideia Central Excluída & 13 & 16,9 \\
\hline & Total & 77 & 100,0 \\
\hline
\end{tabular}

não têm uma alimentação saudável, que correspondem as ideias centrais IC1.1B-" Hábito" e IC1.1D- "Falta de tempo/condição financeira” (Quadro 2).

A ideia central IC.2H -"Comer nos horários certos” (Quadro 3), também foi apontada como um motivo que impede a prática de uma alimentação saudável e faz parte da ideia central
IC1.1C-"Comer fora de casa/comer fora de hora/ Comida pesada e desequilibrada” (Quadro 2), e esta pode ser uma das explicações para o fato dos responsáveis desejarem "cortar e evitar alimentos gordurosos”, mencionado na IC.2I (Quadro 3).

Os discursos IC.2E, IC.2H e IC.2I demonstram uma certa preocupação com a alimentação que contenha mais verduras e legumes, em horários 
certos e livres de gorduras e açúcares (Quadro 3). Contudo, devido aos fatores dificultadores relatados neste estudo, com ênfase na condição financeira e a falta de tempo, os indivíduos acabam se engajando em práticas alimentares inadequadas.

Os responsáveis deste estudo identificaram a alimentação saudável como aquela que depende da condição financeira. Entretanto, é possível ter uma alimentação saudável mesmo com um baixo poder aquisitivo. Com uma orientação adequada pode-se fazer um bom planejamento de compras, observando o que realmente é necessário adquirir para o consumo, comprando, por exemplo, frutas, legumes e verduras da estação, o que torna possível se ter à mesa alimentos saudáveis de maneira econômica. Planejar quando e onde comprar é importante para não se gastar mais do que o necessário e possível ${ }^{32}$.

O discurso IC.2G, Quadro 3, revela que alguns responsáveis não encontram dificuldades para se alimentar de maneira saudável. Estes indivíduos podem não reconhecer suas práticas alimentares inadequadas, o que representa um obstáculo a ser considerado em ações de educação alimentar e nutricional, tendo em vista que esses indivíduos não estarão motivados a realizar alterações dietéticas ${ }^{43}$.

Dos responsáveis que acreditam ter uma alimentação saudável, todos apontaram alguma dificuldade para se alimentar de forma saudável (Quadro 2). Uma explicação para isto seria o fato de muitas pessoas considerarem saudável a prática de ingerir uma ou duas frutas e/ou hortaliças por semana. No entanto, esta pode estar associada a ingestão inadequada e frequente de alimen- tos como gorduras, carboidratos, sal e açúcar. Uma análise quantitativa da alimentação seria necessária para averiguar a periodicidade em que estes responsáveis ingerem alimentos saudáveis e se esta frequência é realmente a esperada para se ter uma alimentação saudável.

\section{Conclusão}

O grupo de responsáveis pelas crianças da Creche tem uma noção do que é uma alimentação saudável, no entanto, esta não é refletida em seus discursos, que evidenciam uma prática alimentar inadequada. Identificou-se dificuldades para a obtenção de uma alimentação saudável através das respostas focadas em recursos financeiros, falta de tempo e hábito alimentar.

Os achados deste estudo sugerem que os responsáveis precisam ter um cuidado maior em relação à sua alimentação, uma vez que seus filhos encontram-se em uma faixa etária em que o padrão alimentar está sendo formado e a inserção inadequada de alimentos pode influenciar e comprometer sua saúde e qualidade de vida.

Entende-se que os responsáveis precisam mudar sua forma de sentir e pensar a alimentação, bem como fazer escolhas alimentares saudáveis. Para que isto ocorra, faz-se necessário propor estratégias no campo da alimentação e nutrição que levem à reflexão, possibilitando aos responsáveis reconhecer e ter uma alimentação saudável, seus benefícios para sua saúde e de seus filhos, bem como transpor barreiras que os impeçam de adotá-la. 


\section{Colaboradores}

IC Bento responsabilizou-se pela concepção, digitação, análise e interpretação dos dados; elaboração do rascunho; revisão crítica do conteúdo; aprovação da versão final do manuscrito. TE França responsabilizou-se pela análise e interpretação dos dados e aprovação da versão final do manuscrito. JMM Esteves revisão crítica do conteúdo; aprovação da versão final do manuscrito.

\section{Referências}

1. Oliveira TSC, Silva MCS, Santos JN, Rocha DS, Alves CRL, Capanema FD, Lamounier JA. Anemia entre pre -escolares - um problema de saude publica em Belo Horizonte, Brasil. Cien Saude Colet 2014; 19(1):59-66.

2. Lelis CT, Teixeira KMD, Silva NM. A inserção feminina no mercado de trabalho e suas implicações para os hábitos alimentares da mulher e de sua família. Saúde em Debate 2012; 36(95):523-532.

3. Boog MCF. Educação em nutrição: integrando experiências. Campinas, SP: Komedi; 2013.

4. Bernardi JR, Cezaro C, Fisberg RM, Fisberg M, Vitolo MR. Estimativa do consumo de energia e de macronutrientes no domicílio e na escola em pré-escolares. Jornal de Pediatria 2010; 86(1):59-64.

5. Briolo MC, Louzada MLC, Drachler ML, Stenzel LM, Vitolo MR. Percepção e atitudes maternas em relação às orientações de profissionais de saúde referentes a práticas alimentares no primeiro ano de vida. J. Pediatr 2013; 89(5):485-491.

6. Martino HSD, Ferreira AC, Pereira CN, Silva RR. Avaliação antropométrica e análise dietética de pré-escolares em centros educacionais municipais no sul de Minas Gerais. Cien Saude Colet 2010; 15(2):551-558.

7. Nascimento APB, Ferreira ML, Molina SMG. Avaliação antropométrica de pré-escolares em Piracicaba, SP: da desnutrição para a obesidade. ConScientiae Saúde 2010; 9(4):707-713.

8. Van Rossem L, Hafkamp-de Groen E, Jaddoe VW, Hofman A, Mackenbach JP, Raat H. The role of early life factors in the development of ethnic differences in growth and overweight in preschoolchildren: a prospective birth cohort. BMC Public Health 2014; 14(1):722.

9. Minayo MCS. Análise qualitativa: teoria, passos e fidedignidade. Cien Saude Colet 2012; 17(3):621-626.

10. Brasil. Ministério da Saúde (MS). Conselho Nacional de Saúde. Resolução no 466, de 12 de dezembro de 2012. Diário Oficial da União 2013; 13 jun.

11. Gomes VLO, Telles KS, Roballo EC. Grupo focal e discurso do sujeito coletivo: produção de conhecimento em saúde de adolescentes. Esc. Anna Nery 2009; 13(4):856-862.

12. Lefevvre F, Lefèvre AMC. Pesquisa de representação Social - um enfoque qualiquantitativo. Brasília: Líber Livro Editora; 2010.

13. Oliveira MM, Silva NN, Menezes RSS, Luiz GV, Palmeira PA. Administrando trabalho e família: um estudo de Caso sobre mulheres profissionais com alto nível de instrução. Oikos Rev Brasileira de Economia Doméstica 2012; 23(1):170-200.

14. França AL, Schimanski E. Mulher, trabalho e família: uma análise sobre a dupla jornada feminina e seus reflexos no âmbito familiar. Emancipação 2009; 9(1):6578.

15. Instituto Brasileiro de Geografia e Estatística (IBGE). Soares C, Sabóia AS. Tempo, trabalho e afazeres domésticos: um estudo com base nos dados da Pesquisa Nacional por Amostra de Domicílios de 2001 e 2005. Rio de Janeiro: IBGE, Coordenação de População e Indicadores Sociais; 2007. [acessado 2014 set. 25]. Disponível em: http://www.ibge.gov.br/home/estatistica/populacao/tempo_trabalho_afdom_pnad2001_2005.pdf. 
16. Leone ET, Maia AG, Baltar PE. Mudanças na composição das famílias e impactos sobre a redução da pobreza no Brasil. Economia e Sociedade 2010; 19(1):59-77.

17. Reia MC, Ramos L. Escolaridade dos pais, desempenho no mercado de trabalho e desigualdade de rendimentos. Rev. Bras. Econ. 2011; 65(2):177-205.

18. Toloni MHA, Longo-Silva G, Goulart RMM, Taddei JAAC. Introdução de alimentos industrializados e de alimentos de uso tradicional na dieta de crianças de creches públicas no município de São Paulo. Rev. Nutr. 2011; 24(1):61-70.

19. Molina MCB, Lopéz PM, Faria CP, Cade NV, Zandonade E. Preditores socioeconômicos da qualidade da alimentação de crianças. Rev Saude Publica 2010; 44(5):785-792.

20. Zimmerman FJ, Bell JF. Associations of television content type and obesity in children. Am J Public Health 2010; 100(2):334-340.

21. Santos CC, Stuchi RAG, Arreguy-Sena C, Pinto NAVD. A influência da televisão nos hábitos, costumes e comportamento alimentar. Cogitare Enferm. 2012; 17(1):65-71.

22. Agência Nacional de Vigilância Sanitária (Anvisa). Alimentação saudável: fique esperto. 2007. [acessado 2014 set 26]. Disponível em: http://www.anvisa.gov.br/propaganda/alimento_saudavel_gprop_web.pdf

23. Moura NC. Influência da mídia no comportamento alimentar de crianças e adolescentes. Segurança Alimentar e Nutricional 2010; 17(1):113-122.

24. Santos CC, Stuchi RAG, Sena CA, Pinto NAVD. A influência da televisão nos hábitos, costumes e comportamento alimentar. Cogitare Enferm 2012; 17(1):65-71.

25. Claro RM, Monteiro CA. Renda familiar, preço de alimentos e aquisição domiciliar de frutas e hortaliças no Brasil. Rev Saude Publica 2010; 44(6):1014-1020.

26. Drewnowski A, Darmon N, Ferguson E, Briend A. Replacing fats and sweets with vegetable and fruits - a question of cost. Am J Public Health 2004; 94(9):15551559.

27. Batalha MO, Luchese T, Lambert JL. Hábitos de consumo alimentar no Brasil: realidade e perspectivas. In: Batalha MO, organizador. Gestão de agronegócios: textos selecionados. São Carlos: Editora UFSCar; 2005. Cap. 2. p. 28-84.

28. Souza AM, Pereira RA, Yokoo EM, Levy RB, Sichieri R. Alimentos mais consumidos no Brasil: Inquérito $\mathrm{Na}$ cional de Alimentação 2008-2009. Rev Saude Publica 2013; 47(1):190S-199S.

29. Bento IC. Perfil Sociodemográfico, Nutricional e Psicossocial dos usuários dos Restaurantes e Refeitório Populares de Belo Horizonte-MG: fundamento para a elaboração de uma Intervenção Educativa Alimentar e Nutricional [dissertação]. Belo Horizonte: Universidade Federal de Minas Gerais; 2012.

30. Marinho FCM, Assao TY, Cervato-Mancuso AM. Percepções e práticas dos diretores e coordenadores acerca da alimentação infantil em creches públicas do município de Jandira, São Paulo, Brasil. Segurança Alimentar e Nutricional 2010; 17(2):40-49.

31. Barbosa RM, Colares LGT, Soares EA. Percepção de responsáveis e recreadores sobre diferentes representações gráficas de guia alimentar para crianças de dois a três anos. Rev. Paul. Pediatr. 2008; 26(4):350-356.
32. Brasil. Ministério da Saúde (MS). Secretaria de Atenção à Saúde. Coordenação-Geral da Política de Alimentação e Nutrição. Guia alimentar para a população brasileira: promovendo a alimentação saudável. Brasília: MS; 2006.

33. Viegas SMF, Lanza FM, Lara MO, Lage AMD, Penna CMM. Alimentação, uma das chaves para a sáude: análise de conteúdo de reportagens da revista veja. $R$. Enferm. Cent. O. Min. 2012; 2(1):78-92.

34. Bertolin MNT. A alimentação saudável na ótica dos adolescentes e o impacto de uma intervenção nutricional com materiais educativos baseados no Modelo Transteórico entre escolares em Brasília - DF [tese]. São Paulo: Universidade de São Paulo; 2010.

35. Fernández LC, Serrab JD, Álvarez JRM, Alberich RS, Jiménez FP. Grasas de la dieta y salud cardiovascular. An Pediatr 2011; 74(3):192-206.

36. Menezes MFG, Tavares EL, Santos DM, Targueta CL, Prado SD. Alimentação saudável na experiência de idosos. Rev. Bras. Geriatr. Gerontol. 2010; 13(2):267-275.

37. Popkin BQ, Adair LS, NG SW. Global nutrition transition and the pandemic of obesity in developing countries. Nutr Rev 2012; 70(1):3-21.

38. Instituto Brasileiro de Geografia e Estatística (IBGE). Pesquisa de Orçamentos Familiares 2008/2009 - Despesas, Rendimentos e Condições de Vida. Rio de Janeiro: IBGE; 2010. [acessado 2014 jun 10]. Disponível em: http://www.ibge.gov.br/home/estatistica/populacao/ condicaodevida/pof/2008_2009/POFpublicacao.pdf World Health Organization (WHO).The Internatio-

39. nal Food and Beverage Alliance's Five Commitments to Action in support of the World Health Organization's 2004 Global Strategy on Diet, Physical Activity and Health. Executive Summary for the 2009-2010 Progress Report. March, 2011. [acessado 2014 jun 10]. Disponível em: http://ifballiance.org/sites/default/files/IFBA_Progress_Report_2009-2010_-_Executive_ Summary.pdf

40. Barbosa RMS, Croccia C, Carvalho CGN, Franco VC, Salles-Costa R, Soares EA. Consumo alimentar de crianças com base na pirâmide alimentar brasileira infantil. Rev Nutrição 2005; 18(5):633-641.

41. Lachat C, Nago E, Verstraeten R, Roberfroid D, Van Camp J, Kolsteren P. Eating out of home and its association with dietary intake: a systematic review of the evidence. Obes Rev. 2012; 13(4):329-346.

42. Proença RPC. Alimentação e globalização: algumas reflexões. Cienc. Cult. 2010; 62(4):43-47.

43. Horwatk CC, Nigg CR, Motl RW, Wong KT, Dishman RK. Investigating Fruit and Vegetable Consumption Using the Transtheoretical Model. Am J Health Promot 2010; 24(5):324-333.

Artigo apresentado em 01/08/2014

Aprovado em 14/11/2014

Versão final apresentada em 16/11/2014 